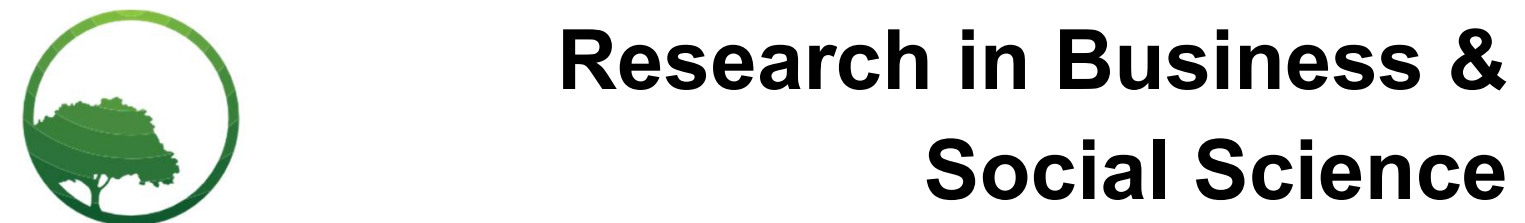

IJRBS Vol 5 No 3, April Issue ISSN: 2147-4478 IJRBS

\title{
The Role of Social Media in Crisis Communication and Crisis Management
}

\author{
Mustafa Emre Civelek
}

Lecturer, Istanbul Commerce University, Istanbul, Turkey

\section{Murat Çemberci}

Lecturer, Istanbul Commerce University, Istanbul, Turkey

\section{Necati Erdem Eralp}

Graduate Student, Istanbul Commerce University, Istanbul, Turkey

\begin{abstract}
Social media and social media tools have improved rapidly and started to influence society especially in recent years. This influence has forced businesses to revolutionize their communication with the external environment. The fact that Web 2.0 has an influence on consumer behavior, and that it makes the consumers stronger; requires faster, more flexible and more sensitive communication processes in businesses. Especially during a time of crisis, a business' communication with the external environment is quite critical. For this reason, the way how the crisis communication is managed through social media is vital for businesses. In this article, the perceptions of how to manage businesses during a time of crisis so that they make minimum loss, is shared.
\end{abstract}

Key words: Crisis Management, Crisis Communication, Social Media, Social Networks, Disinformation

JEL classification: M12, M14

\section{Introduction}

The fact that information is reachable everywhere all the time and it can be broadcasted thank to the improvements of communication technologies and systems, creates new communication platforms which 
causes economic, political, social and cultural transformations in many ways. Along with Web 2.0 technologies getting widespread on the Internet, especially in recent years, social networks have gained extreme importance (Kulakli \& Mahony, 2014). Social media platforms and new media tools like mobile applications which were formed in these networks, has changed mass broadcasting initiative which was based on traditional media establishments like newspaper, radio and television; into individuals and public and private enterprises which are not focused on broadcasting; and this direct broadcasting resulted in individual, social, economic, cultural, political and legal consequences (Scaglione, Giovannetti, \& Hamoudia, 2015).

These progresses of social media also influence businesses. Today, consumers who are Internet users are more demanding and stronger. Social media shares of the costumers include threads as well as opportunities for the businesses. Especially at times of crisis, applying right communication strategies on social media is crucial for businesses (Li, de Zubielqui, \& O'Connor, 2015).

\section{Conceptual Framework}

The basis of the conceptual framework of this study consists of crisis, crisis communication, crisis management, social media and disinformation.

\section{Crisis Concept}

Today, organizations operate in a very dynamic environment. Achievement of their goals and their survivals mostly depend on their adaptation to the environment. Organizational environment is in a constant change, leaving the organizations facing many threats. The survival chance of organizations which cannot find appropriate solutions to these threats on time, has been decreasing (Simon-Elorz, Castillo-Valero, \& Garcia-Cortijo, 2015).

When we examine the threats which threaten the continuity of organizations; it is seen that these dangers have a very ambiguous structure; the conventional and usual methods are insufficient to eliminate them. These are the problems which cannot be unforeseen and hard to understand, that make organizations face situations of crisis. In recent years, the number of crises have been vastly increasing, and crises have been becoming an important part of the organizational life; because of both negative environmental conditions occurring out of their control and failure of their own management policies (Tüz, Haşit, İpçioğlu, \& Suher, 2013; Villa \& Rajwani, 2013).

Organizational crises are situations resulting from people, organizational structure, economy or new technologies; influencing the society. Crises may influence financial structure and fame of organizations negatively. In crisis periods, the increase in the organizational stress affects the organizational climate negatively. The most important reason of the organization stress which occurs in crises is that organizations are obligated to change their goals which have been structured in accordance with their long term strategies. Moreover, depending on the magnitude of the crises, organizational strategies may need to be reviewed completely (Parnell, 2015; Hermann, 1972).

Whereas in some of the resources in the literature, the concept of crisis is approached as a threat; in some of the resources it is evaluated in the aspect of the opportunities arising from it for the organization. Organizations must be prepared for the crises to reduce the possible harms which may occur in crises to minimum, and also maximize the opportunities (Karake-Shalhoub, 1999). The crises in an organization can be defined as situations which can result in important organizational loss where there is a time pressure to make a decision (Mikusova, 2014).

Crises can also be defined as unexpected entities with a potential to create negative results. Because of their unexpected nature, being ready for crises is hard for organizations; and crises which occur unexpectedly may result in deterioration of organizational structure, along with negative outcomes in employees, products, services, financial state and organizational fame. Being ready for crises requires being alert for a crisis all the time, rather than estimating when and how it will occur (Rosenthal \& Kouzmin, 1993). 
In the definitions which pay attention to the opportunity aspect of crises, the concept of crisis is stated as an entity which has the potential of benefiting the organization in case it is managed in the right way. Because during a crisis, the radius of the internal problems will hit the top; covered problems existing before the crisis will emerge. This is why the prerequisite of being ready for a crisis, is having a healthy organizational structure and a strong organizational culture (Sturges, 1994).

A crisis goes through four different phases. These phases are named using medical terms (Kash \& Darling,1998;Darling, Seristo , \& Gabrielsson, 2005):

\section{Prodromal crisis stage}

Acute crisis stage

Chronic crisis stage

\section{Crisis resolution stage}

The first stage of a crisis is "occurrence of the crisis" or "prodromal period". In this period, important clues about a potential crisis start to arise. These warning messages, when noticed, present repetitive messages to the organization, helping to eliminate crisis or to reduce the potential effects of the crisis along with continuous clues. Organizations which stay alert to the inclinations and progresses in their environment are able to be luckier in detecting and preventing the occurrence of a crisis (Paraskevas \& Altinay, 2013; Coombs W. T., 2015).

\section{Crisis Management}

Crisis management, in case of a possible crisis situation, is a process consisting of activities of evaluation of crisis signs, taking and applying necessary precautions in order to recover from the crisis with minimum loss (Simola, 2014). Crisis management is a process including a set of activities like estimation and prevention of crises, getting prepared for them, determining their characteristics, planning recovery and learning mechanisms, reschedule and application(Tüz, Haşit, İpçioğlu, \& Suher, 2013). According to another definition, crisis management is a set of interconnected evaluations and audits which an organization executes in order to prevent crises which are capable of creating serious threats for main product, service, production process, staff, environment and society (Janis, 1989).

Today, administrators must consider where, when, how and in what way a crisis can occur, who and how many people may get influenced; rather than thinking about whether the crisis will influence the business or not. Business administrators must allocate more time to crisis management practice for preventing a crisis which can occur anytime and recovering from it with minimum loss. In summary, businesses must start crisis management practices before a crisis actually occurs (Huang \& Su, 2009).

Crisis management is a decision-making process. Being a special kind of management, it has similar characteristics to strategic management principles. Crisis management aims to make sure organizations are ready for crises while taking necessary precautions to recover from them with minimum cost and maximum profit (Cesta, Cortellessa, \& Benedictis, 2014).

\section{Crisis Communication}

Every institution may face a crisis either resulting from internal or external factors. Being ready for a crisis beforehand is quite important for eliminating its negative effects because crises requires immediate intervention, and time pressure is quite strong. For this reason, today all institutions and organizations must get ready for crises. Crises may occur in many different dimensions and forms, but all of them potentially threaten the feeling of trust shared between the institution and its audience. Determining the reasons resulting in crises beforehand is quite important for developing strategies and planning towards them. Crises may result from weaknesses in the institutional structure along with internal or external environmental threads. Based on the differences of organizations, it can be said that the reasons and the types of crises may vary, but the main reason of crises is failure of integration between institution and its external environment (Nijkrake, Gosselt, \& Gutteling, 2015). 
In times of crises, management of public relations is extremely important. Public relations are effective communication factors before, during and after crisis periods. That's why businesses must review and plan their public relations programs carefully. By this means, businesses can have a plan before a crisis actually happens, have the opportunity of not being caught off their guard in case of a sudden crisis, get minimum harm from possible negative public opinions and negative effects, and moreover, turn the crisis into an opportunity. Crisis communication process and public relations programs are observed to be the most important factors in crisis management efforts. Organizations, when they face with a crisis, are in the position of responding to the crisis quickly, being honest and inform their institutions regularly (Edworthy, Hellier, Newbold, \& Titchener, 2015).

In crisis periods, public relations have great responsibilities in subjects such as creating communication plans, providing information and preventing negative public opinion about the institution. In three periods of the crisis such as before, during and after crisis; public relations programs can be examined in two stages. Frist stage is accepting the existence of the crisis, gaining information about it and mobilizing the crisis management team which was brought together in the preparation for a crisis phase. Second phase is informing organizational environment about the crisis, informing employees, informing target audience and informing the media (Coombs W. T., 2015).

In a crisis time, the behaviors of an institution are evaluated along with the messages it sends. That's why management of these messages is important, and management of the messages means executing behaviors along with execution of communication. Public relations employees communicate to all related internal and external environment during the efforts to create consistency between the expectations of the society and the aims of the institution (Avnel \& Laufer, 2015). Crisis communication is the management of the communication with internal and external environment which will be established in all stages of a crisis. The most suitable communication means must be chosen to convey the necessary messages to the organizational environment (Kadarovaa, et al, 2015).

In an effective crisis communication, just communicating with the media is not sufficient. At the same time, being a relationship is also necessary with various other groups such as government executives, employees, in some cases relatives of the employees, financial groups and consumers. Even if the communication type for each group differs, the important part is being compatible and consistent with the messages which are sent to the mentioned groups. Institutions are judged for their attitude and behavior towards crisis, rather than the reasons of the crisis. When an institution gets ready and plans for a possible crisis, this shows that their attitude will be impressive, moderate and consistent (Meer \& Verhoeven, 2014; Rutsaert \& et al., 2014).

\section{Web 2.0}

The websites which collaborates with users, where users are content providers, are called Web 2.0 websites. This type of websites gives their users the opportunity to produce and share content. The time period between 1990 and 2000 is called Web 1.0 period. Web 1.0 period is the period of static websites. These kinds of websites interact with their visitors at a very low level. The time period between 2000 and 2010 is named as Web 2.0 period (Kaplan \& Haenlein, 2010).

This period is the one hosting the emergence the websites which collaborate with users like Wikipedia and Twitter. The most important feature of Web 2.0 is its dynamic structure. Dynamic features mean being in an interaction with users. The best examples of transition from Web 1.0 to Web 2.0, are sharing websites, websites like Wikipedia where users produce content, social network websites like Facebook and Internet diaries called blogs (Civelek, 2009).

Since the popularity of the Web 2.0 websites in the beginnings of 2000's, consumers have been more knowledgeable, conscious and demanding. The high impact of comments and complaints of consumers about products and services in social networks, besides posing a threat for businesses, also creates opportunities for them to stand out among their rivals. Because in participation systems, only a low percentage of users will make enough effort to add value, these systems get stronger with increasing number of users. However, increasing number of users makes it harder to keep track of the content. This 
situation emerges as a disadvantage for Web 2.0 applications. It is extremely hard to confirm the accuracy of the content shared in Web 2.0 applications. That's why some people claim that Web 2.0 content is unprofessional and weak, that it damages the culture created by educated writers by replacing it with nonprofessional user culture. Mixture of trustworthy content and untrustworthy unprofessional content brings terrible information pollution along with it. As a result, valuable contents become hard to distinguish by getting mixed with invaluable ones. This situation brings the risk of making the whole content an uncontrolled and invaluable pile. However, the transformation of users to content-creators is a very important progress in terms of creating collective consciousness and democracy culture (Civelek, 2009).

\section{Social Media and Networks}

Social media has become the most effective communication means in the whole world in a short time because of its sharing networks' ability and power to keep masses posted, entertained and impressed. This interest in social media caused many digital agencies to be born, in the meantime attracting the attention of the traditional media (Searson, Hancock, Soheil, \& Shepherd, 2015). The reason of the positive image of social media on societies is buried in the characteristics of social media. Social media characteristics are listed below (Odyakmaz, 2013):

- Interactivity: Virtual communication environments such as MSN, Facebook, Twitter, and MySpace are interactive environments. While in traditional media, communication is one-way, and messages are produced by a specific source according to specific rules; in social media, communication is both ways. Individuals are both producers and consumers in all stages of communication.

- Instantaneity: Transferring the messages which can be accomplished by traditional media in an instant manner, is the main feature of the communication through the Internet.

- Not pursuing a commercial profit goal: It's implied that individuals using the media for communication purposes do not pursue a commercial goal. On the other hand, each social media environment is already built up for commercial purposes; and users come across to advertisements at every step they take.

- Serving to individuals and masses: Whereas traditional media aims at masses, and it is a one-way communication; social media aims at communicating with both masses and individuals.

- No requirement for professionality: While production and transfer of messages requires professionality in traditional media, it is enough to be a computer user for these purposes in social media.

- Not giving importance to hierarchic relationships or classlessness: In social media, a sincere communication exists where hierarchical relationships can be ignored. However, this is applicable when identities are hidden. When identities are visible, it is not possible to call someone who is in an upper-class hierarchical level in society, "you". Social media is an environment where people from all classes in a society can get together and talk, without paying attention to education, job, gender, income criteria.

- Being beyond space and time: Especially after the improvements in mobile communication technologies, time and place of communication through social media has become unimportant. Everyone, everywhere, whenever they want (as long as they are in coverage zone), can send and receive messages.

- Changeability of messages: In traditional media, it is not possible to undo or change a message which has been sent. However, in social media environment, messages which have been sent can be undone, edited, changed.

- Difference in Property Structure: Social media is also a property of a specific individual or institution, like traditional media. However, property structure of social media does not affect the content, in contrast to traditional media. Profits of the boss are not primary interest of social media users. In this aspect, it can be claimed that it is freer.

- Information pollution: Social media serves to the creation of an information society which gives the false impression that "it is very easy to access information", as exactly today's capitalist system tries to achieve. 
In a society, it is known that there are three factors affecting how ideas spread among individuals. First one of them is spreading a message easily in a simplified manner. The Internet and social media play and important role in this manner. The second factor is making the messages easy to understand. The third factor affecting how ideas spread among society is mentioning a message for a long time in a polyphonic way. Social media plays an important role for that. Especially \# (hashtag) application in Twitter, make a message shared by thousands of people. Negative, unreal, distorted and manipulative news and messages also shared with public in this way. Studies reveal that the more people share an information, message or rumor spreading on social media, the more accredited it becomes; and after a certain threshold, it is perceived as the truth. Especially the retweet count and speed, effect of twitters of a tweet on Twitter, are important factors on how widespread a message gets. Also, the content of a message on Twitter affects the spreading speed of a message (Fischer \& Reuber, 2011).

One of the most important features of social media is that it creates opportunity for user based information production. This feature, which is explained above, allows social media to produce and share uncontrolled and uncensored information. Another feature which makes social media usage attractive, produced message and information is transferred to long distances and big crowds in the most economical way. A produced message or various files such as an image, video... etc. which is wanted to be shared, can be transferred to people belonging to all kinds of socioeconomic group in various parts of the world in a short time. This empowers the individuals and groups who want to be heard through social media (Wagner, Vollmar, \& Wagner, 2014).

Individuals who lose contact with the people thinking alike, and who get lost in the muteness spiral created by the system through the one-way communication of traditional media; through social media, discover that they are not alone, and use the power of joining hands. In order to understand the power of social media, it is enough to observe Gezi Park Events took place in Turkey in June 2014. While by the time events had started, there were 1.8 million Twitter users; after a few days, number of users reached up to 10 million. Turkey became the main topic of conversation in the world with 15 million accesses. Number of active Twitter users was 1.8 million on the day of starting of the events which is May 29 2014, but it reached up to 10 million on June 102014 (Odyakmaz, 2013).

There are positive and negative elements of the new media. The positive aspect of the new media is that it creates collective consciousness and democracy culture; and the negative aspect of the new media is the spread of information pollution in general society through the mixture and indistinguishability of trustworthy and untrustworthy information. The collective consciousness which social media creates, provides individual participation not only for purposes of daily news, information and communication; but also nearly in all political, ideological, financial, cultural fields. It is seen that now the new media has a barnburner and quick-spread structure. The new media is an environment where individuals are the resources of the news and auto-censorship does not exist. The new media is a grassroots movement (Kassam, 2013).

\section{Social Media and Disinformation}

Two important features of the new media, and social media along with it, which attract individuals at most; are that it does not require professionalism and the difference in its property structure, also these two channels make it an uncontrolled information source where this information cannot be checked. Often mentioned feature of new media and especially social media, "everyone can produce content", at first seemed as freedom to talk and an opportunity for the improvement of democracy; but later, with more contribution which brings more information, this situation has become an obstacle for reaching trustworthy information. The questionable information concept discussed for the information gained through the Internet, today is valid also for social media (Anouar, 2014).

Every day, the data uploaded to the Internet for various purposes, are kept in databases easily and brought into the use of search engines. The increase in the information which can be accessed in the Internet has made it difficult to reach true, consistent and trustworthy information (Fırat \& Kurt, 2015).

While social media and social media tools are considered as places where individuals can express themselves freely, uncontrollability and legal gaps made social media a channel suitable for disinformation. 
Manipulation, which is one of the most important problems in the digital era, is used quite often in social media; and sometimes consciously, sometimes without checking the source and trustworthiness of information, various false contents are shared by millions of users in social media (Lysenko \& Desouza, 2012).

\section{Examples of Social Media Crisis}

\section{Onur Air Social Media Crisis}

At October 25 2011, Onur Air started a campaign on their Facebook page. While announcing they will donate money to the people who got harmed during the earthquake in Van, Onur Air stated that they will donate 0.5 TRY for every new Facebook subscriber, in total 250000 TRY donation.

A few hours after the earthquake, Onur Air posted a message on their Twitter and Facebook pages saying "We wish health for all the citizens influenced by the disaster happened in Van and our condolences is to the people who lost their lives and to their relatives." and this post was liked by 389 people. Then social media users started to react to it seriously. The users who blame Onur Air for this campaign, created a pressure on Onur Air expressing that they require being a subscriber to their page as a prerequisite, whereas a donation should be complimentary. The users, reminding them that many companies and institutions make complimentary donations to Van, blamed Onur Air for self-seeking. Onur air started to delete the negative comments although they could not inhibit reactions; and they received even more reactions. Then Onur Air announced that the campaign is over in an acrimonious manner. This acrimonious manner made followers even angrier. So Onur Air published a copy of the bank receipt of their donation; and as a third announcement, apologized for the misunderstandings (Bat \& Yurtsever, 2014).

\section{BP Mexico Gulf Crisis}

At April 20 2010, there was an explosion in a well operated by BP in Mexico Gulf, and 38 hours after the explosion, oil started to gush into the sea. It was announced that a $200 \mathrm{~km}$ long coastline was affected by the oil and 15 million liters of raw petrol flew into the sea daily. It was announced that this number will have reached up to 800 million liters by the time the well is closed. Along with this disaster, over 400 animal and plant species got endangered. In the accident, 11 workers were dead and 17 workers were injured. After the accident, there were a lot of reactions in social media accounts. Greenpeace organized a prize logo competition for BP.

Because BP did not have a crisis management plan for this accident, and because of the announcements of BP administrator Tony Hayward saying that "There are others who pollutes the environment more than we do" or "We do not have enough equipment for this matter", caused the reactions to increase. Increasing reactions in social media and anti-BP pages put the company in an even more difficult position. Moreover, coming out of the false leakage number announced to public and photoshopped photographs put the company in an even more difficult situation. BP took responsibility only after weeks. All efforts to close the well and clean the gulf were published in full detail. A YouTube channel was purchased, and all operations were shared with public daily. Although they were late, BP started to broadcast the operations live (SlideShare, 2015).

\section{Conclusion}

There are many studies in the literature showing that communication management is the most important element of crisis management (Coombs W. T., 2015; Avnel \& Laufer, 2015; Cesta, Cortellessa, \& Benedictis, 2014; Edworthy, et al, 2015). Today, the most important communication channel is the Internet. Along with the improvements of Web 2.0 technologies on the Internet, Social media websites has come into prominence since 2000 s. The collective consciousness created by consumers on social media was non-negligible for businesses in their communication with their environment (Kadarovaa, Mihalcovab, Kadarc, \& Vidad, 2015; Fischer \& Reuber, 2011; Kassam, 2013). Hence, social media communication has become one of the most important tools in crisis management (Wagner, et al. 2014; Bat \& Yurtsever, 2014). 
There are three stages in crisis management in businesses. The first one of these stages is, pre-crisis period; second one is crisis period; and the third one is post-crisis period. In all three stages, there are strategies which businesses must develop (Edworthy, et al. 2015; Hermann, 1972; Kadarovaa, et al. 2015). Using social media as a communication tool is important in order to be effective with these strategies (Kash \& Darling, 1998; Parnell, 2015).

The power and effectiveness of social media on businesses and consumers, forces businesses to think carefully and strategically more than ever (Cesta, et al., 2014; Villa \& Rajwani, 2013). Crisis management starts before the occurrence of an actual crisis environment and a good crisis management continues with being distant to a crisis. Being distant to a crisis requires detecting the factors which may lead to a crisis, and developing strategies to prevent these factors. Thus, businesses at least can eliminate the internal crisis factors. However, there are external factors which may lead to a crisis, too. The studies in the literature express that businesses almost do not have any control over external factors, but the strategies developed to cope with crisis beforehand is important. Because the damage a company gets from a crisis is not the same for a business with a crisis scenario and a business without a crisis scenario and a crisis strategy. There are many studies showing that businesses with a crisis scenario get minimum damage from crisis which occurs because of external reasons (Avnel \& Laufer, 2015; Coombs., 2015 (Edworthy, et al. 2015).

The most important behavior businesses must adopt in case of a crisis resulting either from internal or external factors, is communicating with consumers through the fastest and the most appropriate channel (Rutsaert \& et al., 2014; Sturges, 1994). Because social media is an environment where disinformation occurs often, quickly responding to communication among consumers on social media prevents disinformation. While it is necessary to use this communication channel effectively, many businesses cannot use this communication channel correctly. In this article, examples of usage of the new communication channel are mentioned; and the importance of it in crisis management is emphasized.

The most important limitation of this research is the lack of empirical analysis. Because the main objective of this research is to construct a base for the future studies. As a detailed literature base this paper clarifies the relation between crisis management and the use of social media in new business environment. For future researches this relation would be studied empirically.

\section{References}

Anouar, L. M. (2014). On-line Political Participation: Fractures and Inequality Between the Citizens. International Conference on Communication and Education in Knowledge Society. 163, pp. 257263. Procedia - Social and Behavioral Sciences.

Avnel, T., \& Laufer, D. (2015). Exploring the effectiveness of creating regulatory fit in crisi communications: Can it change perceptions of media coverage during a crisis. Business Horizons, 58(2), 149-156.

Babacan, M. E., Haşlak, I., \& Hira, İ. (2011). Sosyal Medya ve Arap Baharı. Akademik İncelemeler Dergisi, 6(2), 63-92.

Bat, M., \& Yurtsever, Ç. (2014). Sosyal Medyada Kurumsal Kriz Yönetimi: Onur Ailr Örneğl. Gümüşhane Üniversitesi İletişim Fak. Elektronik Dergisi, 2(3), 197-223.

Cesta, A., Cortellessa, G., \& Benedictis, R. (2014). Training for crisis decision making - An approach based on plan adaptation. Knowledge-Based Systems, 58(1), 98-112.

Civelek, M. E. (2009). İnternet Çağı Dinamikleri. İstanbul: Beta.

Coombs, W. T. (2015a). The Value of Communcation During a Crisis: Insight from strategic communication research. Business Horizons, 58(2), 141-148.

Coombs,W.T.(2015b). What Equivocality Teaches Us bbout Crisis Communication. Journal of Contingencies and Crisis Management, 23(3), 125-128. 
Darling, J., Seristo , H., \& Gabrielsson, M. (2005). Anotomy of Crisis Management: A Case of Focusing on a Major Cross-cultural Clash within DaimlerChrysler. The Law, Technology and Arts, 3(5), 343360.

Edworthy, J., Hellier , E., Newbold, L., \& Titchener, K. (2015). Passing Crisis and Emergency Risk Communications: The Effects of Communication Channel, information type, and repetition. Applied Ergonomics, 48(1), 252-262.

Fırat, M., \& Kurt, A. (2015). İnternette Bilgi Kirliliği Ölçeğinin Geliştirilmesi ve Uygulanması. Eğitimde Kuram ve Uygulama, 11(1), 89-103.

Fischer, E., \& Reuber, R. (2011). Social interaction via new social media: (How) can interactions on Twitter affect effectual thinking and behavior? Journal of Business Venturing, 26(1), 1-18.

Hermann, C. (1972). International Crises: Insights from Behavioral Research. New York: New York: Free Press.

Huang, Y.-H., \& Su, S. (2009). Determinants of consistent, timely, and active responses in corporate crises. Public Relations Review, 35(1), 7-17.

Janis, I. (1989). Crucial Decisions: Leadership in Policymaking and Crisis Management. New York: The FreePress.

Kadarovaa, J., Mihalcovab, B., Kadarc, G., \& Vidad, M. (2015). Strategy Map for the Crisis Communication. Procedia Economics and Finance, 23(1), 1119-1124.

Kaplan, A. M., \& Haenlein, M. (2010). Users of the world, unite! The challenges and opportunities of Social Media. Business Horizons, 53, 59-68.

Karabulut, B. (2014). Algı Yönetimi. İstanbul: Alfa.

Karake-Shalhoub, Z. (1999). Organizational Downsizing, Discrimination and Corporate Social Responsibility. Westport: Greenwood Publishing.

Kash, T. J., \& Darling , J. (1998). Crisis management: prevention, diagnosis and intervention. Leadership \& Organization Development Journal, 19(4), 179-186.

Kassam, A. (2013). Changing society using new technologies: Youth participation in the social media revolution and its implications for the development of democracy in sub-Saharan Africa. Education and Information Technologies, 18(2), 253-263.

Kulakli, A., \& Mahony, S. (2014). Knowledge Creation and Sharing with Web 2.0 Tools for Teaching and Learning Roles in So-called University 2.0. 10th International Strategic Management Conference 2014. 150, pp. 648-657. Procedia - Social and Behavioral Sciences.

Li, H., de Zubielqui, G., \& O'Connor, A. (2015). Entrepreneurial networking capacity of cluster firms: a social network perspective on how shared resources enhance firm performance. Small Business Economics, 45(3), 523-541.

Lysenko, V. V., \& Desouza, K. (2012). Moldova's internet revolution: Analyzing the role of technologies in various phases of the confrontation. Technological Forecasting and Social Change, 79(2), 341361.

Meer, T. G., \& Verhoeven, J. (2014). Emotional crisis communication. Public Relations Review, 40(3), 526536.

Mikusova, M. (2014). Multiple Aproach to the Term of Crisis. International Conference on Economics, Management and Development (pp. 124-132). Interlaken: Springer.

Nijkrake, J., Gosselt, J., \& Gutteling, J. (2015). Competing frames and tone in corporate communication versus madia coverage during the crisis. Public Relations Review, 41(1), 80-88. 
Odyakmaz, N. A. (2013). Özgürlük Alanı Olarak Sunulan Sosyal Medya ve Taksim Gezi Parkı Eylemleri. Akdeniz İletişim Dergisi, 210, 202-217.

Paraskevas, A., \& Altinay, L. (2013). Signal detection as the first line of defence in tourism crisis management. Tourism Management, 34, 158-171.

Parnell, J. A. (2015). Crisis Management and Strategic Orientation in Small and Medium-Sized Enterprises ( SMEs) in Peru, Mexico and the United States. Journal of Contingencies \& Crisis Management, 23(4), 221-233.

Rosenthal, U., \& Kouzmin, A. (1993). Globalizing an Agenda for Contingencies and Crisis Management: An Editorial Statement. Journal of Contingencies \& Crisis Management, 1(1), 1-12.

Rutsaert, P., \& et al. (2014). Social media as a useful tool in food risk and benefit communication? A strategic orientation approach. Food Policy, 46(1), 84-93.

Scaglione, M., Giovannetti, E., \& Hamoudia, M. (2015). The diffusion of mobile social networking: Exploring adoption externalities in four G7 countries. International Journal of Forecasting, 31(4), 1159-1170.

Searson, M., Hancock, M., Soheil, N., \& Shepherd, G. (2015). Digital citizenship within global contexts. Education and Information Technologies, 20(4), 729-741.

Simola, S. (2014). Teaching corporate crisis management through business ethics education. European Journal of Training and Development, 38(5), 483-503.

SlideShare. (2015). Retrieved from http://www.slideshare.net/hakancakmak/british-petrol-kriz-ynetimi

Simon-Elorz, K., Castillo-Valero, J., \& Garcia-Cortijo, M. (2015). Economic Performance and the Crisis: Strategies Adopted by the Wineries of Castilla-La Mancha (Spain). Agribusiness, 31(1), 107-131.

Sturges, D. (1994). Communicating Through Crisis. Management Communication Quarterly, 7(3), 297-316.

Tüz, M., Haşit, G., İpçioğlu, İ., \& Suher, İ. (2013). Kriz İletişimi ve Yönetimi. Eskişehir: Anadolu Üniversitesi.

Villa, M. A., \& Rajwani, T. (2013). The mirror trap Do managerial perceptions influence organizational responses to crises? Academia-Revista Latinoamericana De Administracion, 26(1), 170-188.

Wagner, D., Vollmar, G., \& Wagner, H. (2014). The impact of information technology on knowledge creation: An affordance approach to social media. Journal of Enterprise Information Management, 27(1), 31-44. 